\title{
QUEM NÃO É VISTO, NÃO É LEMBRADO: SOCIABILIDADE, ESCRITA, VISIBILIDADE E Memória na São PaUlo da PIXAÇão
}

Alexandre Barbosa Pereira Universidade Federal de São Paulo

\begin{abstract}
O artigo discute o modo como a pixação na cidade São Paulo, protagonizada por jovens dos bairros da periferia, configura um dispositivo de sociabilidade, reconhecimento e memória. Nesse dispositivo, aquele que consegue gravar seu nome no maior número de lugares e de maior destaque alcança maior notoriedade. A pixação configura, assim, uma escrita peculiar que esses jovens gravam na paisagem urbana e que faz sentido principalmente para eles, que sabem ler os muros. Por meio dessa escrita, eles criam referências próprias no espaço urbano e recriam a cidade, mesmo que em contraposição à maioria da população, que não vê com bons olhos sua atividade.
\end{abstract}

Palavras chave: pixação, sociabilidade, memória, escrita, juventude, paisagem urbana

\section{JOVENS ARTEIROS}

Após conseguir a proeza de pixar a sua marca, \#DI\#, no prédio do Conjunto Nacional, importante edifício de São Paulo, situado na Avenida Paulista, considerado um dos símbolos da arquitetura modernista na cidade, o autor do feito ligou para um jornal popular de São Paulo afirmando ser um morador e que havia visto quem tinha pixado o Conjunto Nacional. Esse fato aconteceu nos anos 1990 e a reportagem foi publicada sem que se soubesse que o morador era, na verdade, quem havia realizado a arte.

O Conjunto Nacional, que fica na Avenida Paulista, 2.073, foi alvo de pichações no setor residencial, que tem entrada pela rua Augusta, em Cerqueira César. Segundo um morador, que pediu para ser identificado apenas como $\mathrm{Di}$, os pichadores podem ter entrado no prédio pulando de cima de um orelhão para o beiral da fachada. Dali, teriam quebrado uma janela, no $1^{\circ}$ andar. Ele contou que, além de quebrar o vidro e amassar essa janela, os invasores arrombaram portas. A administração do prédio, que não registrou a ocorrência na Polícia, negou as informações, confirmando apenas que houve pichação. Di afirmou que ficou apavorado com a situação. Segundo ele, o esquema de segurança do prédio não poderia permitir esse tipo de ação, visto que há homens fazendo ronda por dentro e por fora. "Â noite essa segurança é reforçada", destacou. Ele 
tentou apurar maiores detalhes do que aconteceu, mas o porteiro e o segurança disseram que não viram nada (Recorte de jornal extraído do Álbum Só Pixo s/d).

Além de contar como realizou a façanha, \#DI\# tentou ressaltar as dificuldades encontradas para pixar o Conjunto Nacional, justamente para demonstrar a ousadia da ação. \#DI\# é considerado um dos mais importantes pixadores de São Paulo de todos os tempos. Ele teria realizado grandes feitos, deixando sua marca em lugares de difícil acesso e arriscados. Os outros pixadores lembram-se de \#DI\# quase como um herói ou mesmo um mártir, já que ele foi assassinado por motivo não esclarecido. ${ }^{1}$

Também na década de 1990, dois jovens realizaram outro ato dos mais ousados da pixação paulistana. Eles viajaram 400 quilômetros até a cidade do Rio de Janeiro e deixaram suas marcas na famosa estátua do Cristo Redentor. Para indicar que vinham de São Paulo, ainda escreveram: "Z. Oeste de São Paulo - Apavoramos". Não satisfeitos e a fim de garantir a almejada notoriedade, ligaram para a Rede Globo de televisão e anunciaram a proeza. Os dois acabaram sendo presos, pois foram identificados por terem deixado cair um dos bilhetes da passagem de ônibus de São Paulo - alguns afirmaram que propositalmente. O fato, entretanto, alcançou a repercussão desejada por eles, tornando-os conhecidos em todo o Brasil. Em São Paulo, foram idolatrados pelos colegas ${ }^{2}$.

Nos anos 2000, outras ações de grande ousadia foram realizadas, como a pixação da Faculdade Belas Artes, na qual um aluno convidou pixadores para deixar suas marcas nas dependências da instituição como trabalho de conclusão de curso, o ataque às obras de arte da Galeria Choque Cultural e aquela que é considerada a mais contundente das ações dos últimos tempos, a invasão de um andar da Bienal de Artes de São Paulo, que havia sido deixado vazio propositalmente, devido a problemas financeiros. $\mathrm{O}$ andar vazio dessa Bienal de Artes de 2008 gerou muita controvérsia, o que acabou levando muitos a denominarem a exposição desse ano como a Bienal do Vazio. A polêmica, entretanto, acentuou-se ainda mais quando um grupo invadiu o prédio da Bienal e deixou suas marcas nas paredes brancas do andar vazio da exposição. Nesse evento, Carolina Pivetta foi presa e tornou-se um símbolo desse movimento de invasão e contestação da Bienal do Vazio, chegando a mobilizar o ministro da cultura da época, Juca Ferreira, que, segundo matéria do jornal Folha de São Paulo de dezembro de 2008, pediu ao governador em exercício do estado de São Paulo, José Serra, que intercedesse pela libertação da jovem.

Essas são algumas das inúmeras "artes" que os pixadores paulistanos realizaram e continuam a realizar com o intuito de colocar suas grafias em evidência. E aí os próprios se perguntam, o que eles seriam, artistas ou arteiros? Numa clara brincadeira com a ambiguidade do termo: arteiros, que na verdade designa meninos ou meninas que aprontam traquinagens, mas que no caso em questão aponta para que nestas travessuras, ou transgressões, haveria também um sentido artístico. A expressão arteiros, aliás, é bastante interessante para designar uma outra ambiguidade, a da recepção que a atividade destes jovens tem na cidade de São Paulo e em muitas outras grandes cidades brasileiras. Muitas vezes, as ideias de vandalismo, sujeira e poluição visual são definições logo levantadas ao se discutir o que seria esta forma de expressão urbana que é vista por quase toda a paisagem paulistana. As dimensões do vandalismo, da

$1 \quad C f$. fotografia de capa deste número dos Cadernos de Arte e Antropologia. Todas as imagens do artigo foram captadas pelo autor.

2 Essa história está descrita em matéria de jornal nas páginas do álbum Só Pixo e também me foi contada por outros pixadores. 
poluição visual ou da rebeldia e da transgressão são as mais enfatizadas por grande parte da população paulistana e da imprensa.

Contudo, para os pixadores, a rede de sociabilidade e reconhecimento que eles tecem a partir dessa prática tão malvista revela-se o elemento mais importante. Em sua maioria, eles são homens, jovens (predominantemente com idade entre 13 e 25 anos), pobres e moradores dos bairros periféricos de São Paulo. Por meio da pixação, circulam por diferentes espaços da cidade, desbravando-a e estabelecendo relações com outros jovens. Nessa atividade, aqueles que conseguem pixar no maior número de lugares e nos mais arriscados obtêm maior reconhecimento dos colegas. Entre 2001 e 2007, acompanhei de perto as dinâmicas de relações de sociabilidade e apropriações do espaço urbano estabelecidas pelos adeptos dessa atividade por causa de minha pesquisa de mestrado sobre o tema, defendida em 2005. É, principalmente, a experiência que vivenciei e observei nesse período que relatarei e analisarei aqui.

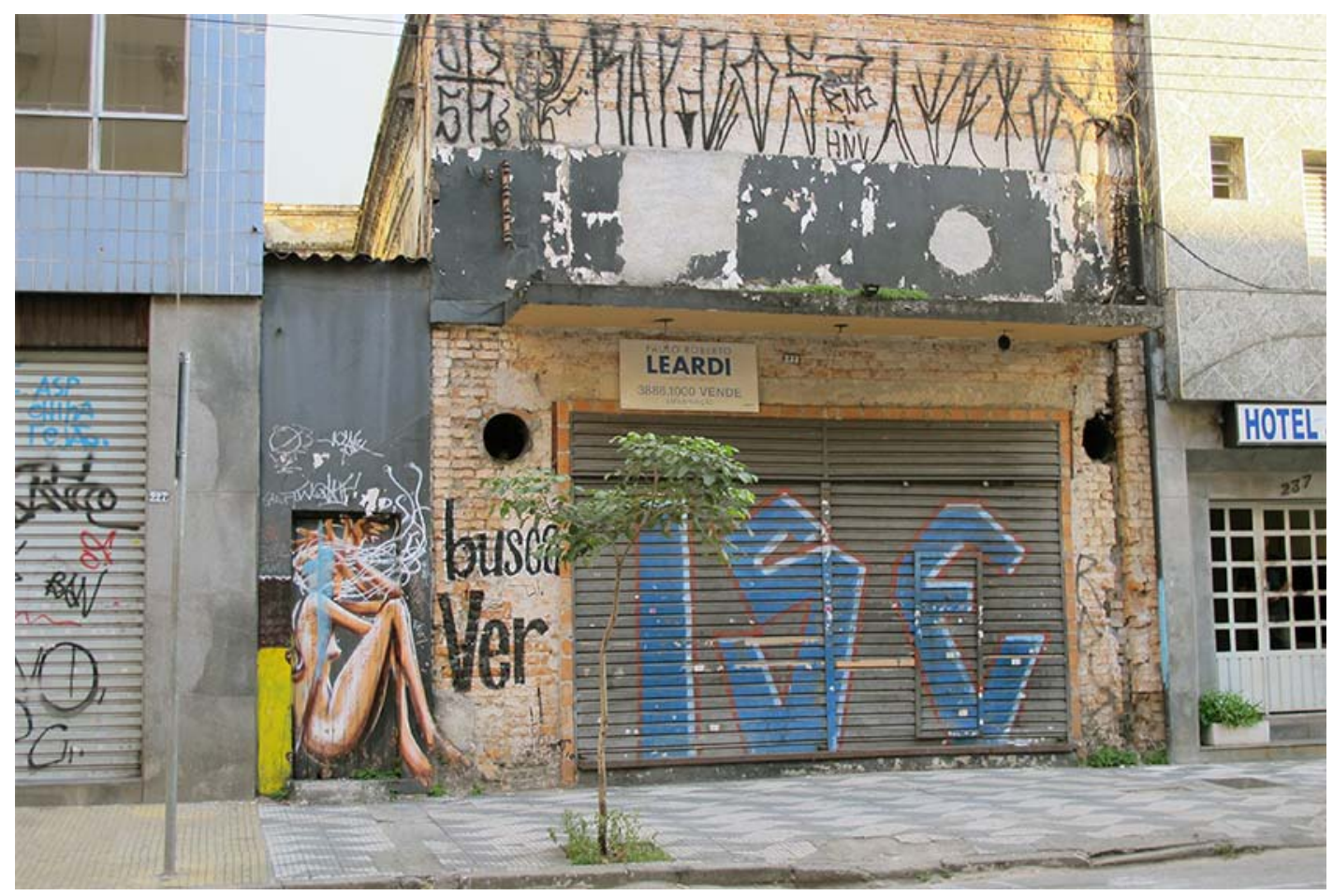

Diferentes expressões visuais convivem na paisagem paulistana, 2012.

Em São Paulo, a pixação está numa relação bastante paradoxal com outra forma de expressão visual urbana, o grafite. Ao mesmo tempo, em que ambas têm uma mesma origem e formas de expressão similar, elas também têm pontos de afastamento e mesmo de controvérsia. O grafite é considerado por muitos segmentos sociais como uma forma de expressão artística que embelezaria a cidade como contraposição às pixações. $\mathrm{O}$ que se percebe então é que as relações entre essas duas modalidades de expressão visual são muito mais imbricadas do que coloca o senso comum. A ascensão de muitos grafiteiros ao status de grandes artistas, como é o caso dos Gêmeos, entre outros com trabalhos internacionais, elevou a fama do grafite paulistano e indiretamente, por conta desta complexa relação com a pixação, esta última acabou sendo impulsionada junto. Em São Paulo, no bairro da Vila Madalena, conhecido por ser um bairro de artistas e por sua intensa vida cultural - por isso um dos bairros preferidos de muitos grafiteiros - surgiram duas galerias de arte voltadas para o grafite, a Choque Cultural - cujas 
obras sofreram uma intervenção dos pixadores como relatado mais acima por ter sido vista como uma deturpação do princípio de subversão da arte urbana - e a Grafiteria. Embora a ênfase desses espaços seja no grafite, elas não deixam de abordar também a pixação. Inclusive, de um dos artistas dessas galerias, o Boleta - que se identifica como grafiteiro e pixador - é que partiu uma das iniciativas que trouxe à tona mais fortemente a questão da pixação como uma forma de arte: o livro "Ttsss... A Grande Arte da Pixação em São Paulo, Brasil”, lançado em 2006.

O livro de Boleta foi produzido em conjunto com a artista plástica Pinky Wainer, o colunista do jornal Folha de São Paulo Xico Sá e do fotógrafo, também ligado a Folha, João Wainer. Com imagens de pixações e de folhinhas, papéis com assinaturas recolhidas nos pontos de encontro desses jovens na cidade, concede à pixação o status de arte. A partir dessa série de eventos, uma parte da imprensa começou a dirigir outro olhar para esta manifestação. Em outra matéria do jornal Folha de São Paulo, de 21/01/2006, que fala do lançamento do livro, por exemplo, o título é "A Arte do pixo", o que já demonstra certa concessão e uma mudança da postura de alguns segmentos. No entanto, a própria Pinky Wainer, que não só colaborou com o livro como é uma das idealizadoras da editora que o lançou, reconhece que o grafite é muito mais fácil de ser assimilado do que a pixação: "Acho que o grafite é mais facilmente absorvido, tem o colorido. A pichação, não. Ali tem uma coisa pesada da cidade, incomoda. Quem vai querer ter uma obra daquelas em casa?" (Revista da Folha 26/03/2006).

Essa mudança do foco sobre a pixação chamou atenção de outra jornalista, Nina Lemos, que em matéria para a Revista da Folha de São Paulo, aborda a maior aceitação do grafite e da pixação por parte de certa classe média "moderna" ligada à moda, design e artes em geral. Nina Lemos afirmou ter ficado espantada ao ver os "moderninhos classe média" no lançamento do livro do Boleta no Galpão K. Segundo ela, alguns pixadores foram convidados para o evento e marcaram o espaço. Pinky Wainer expressou sua opinião a respeito deste evento como algo maravilhoso, "uma manifestação artística de verdade". Essa mudança de enfoque intensificouse ainda mais após uma das mais notáveis artes: a invasão do pavimento vazio da $28^{\mathrm{a}}$ Bienal de Artes de São Paulo, em 2008, que proporcionou um convite a alguns pixadores para participarem da 29a Bienal de Artes de São Paulo, em 2010. Nesse ano, outra polêmica atraiu os holofotes para a pixação paulistana, a obra Bandeira branca de Nuno Ramos, que mantinha três urubus presos num viveiro no vão central do prédio da Bienal, foi invadida e marcada por um dos artistas/pixadores convidados, Djan Ivison, com a seguinte inscrição: "liberte os urubu"3.

Contudo, se há uma grande aceitação do grafite pela cidade e uma grande rejeição à pixação, não se deve pensar que o grafite não está livre de também ser perseguido e de ser apagado dos muros da cidade. A prefeitura municipal tem, aliás, como política de combate às intervenções visuais pintar muros com tinta cinza. Em 2008, por exemplo, gerou grande polêmica uma ação do poder público municipal que apagou um painel de grafite na Avenida 23 de Maio, feito pelos Gêmeos com outros grafiteiros. $\mathrm{O}$ argumento contra a ação foi o de que se tratava de uma obra de arte, pois os irmãos Gustavo e Otávio Pandolfo, os Gêmeos, já expunham inclusive em importantes museus de arte do mundo, como o Tate Modern, em Londres. A prefeitura de São Paulo pediu desculpas, disse que havia se enganado e cedeu outro espaço para que o mural fosse refeito. $\mathrm{Na}$ imagem abaixo, grafiteiros brincam com essa ação da prefeitura de cobrir as intervenções visuais na paisagem urbana com tinta cinza.

3 Para ler mais sobre essa ação dos pixadores, ver o artigo de Sérgio Franco, 2010. 


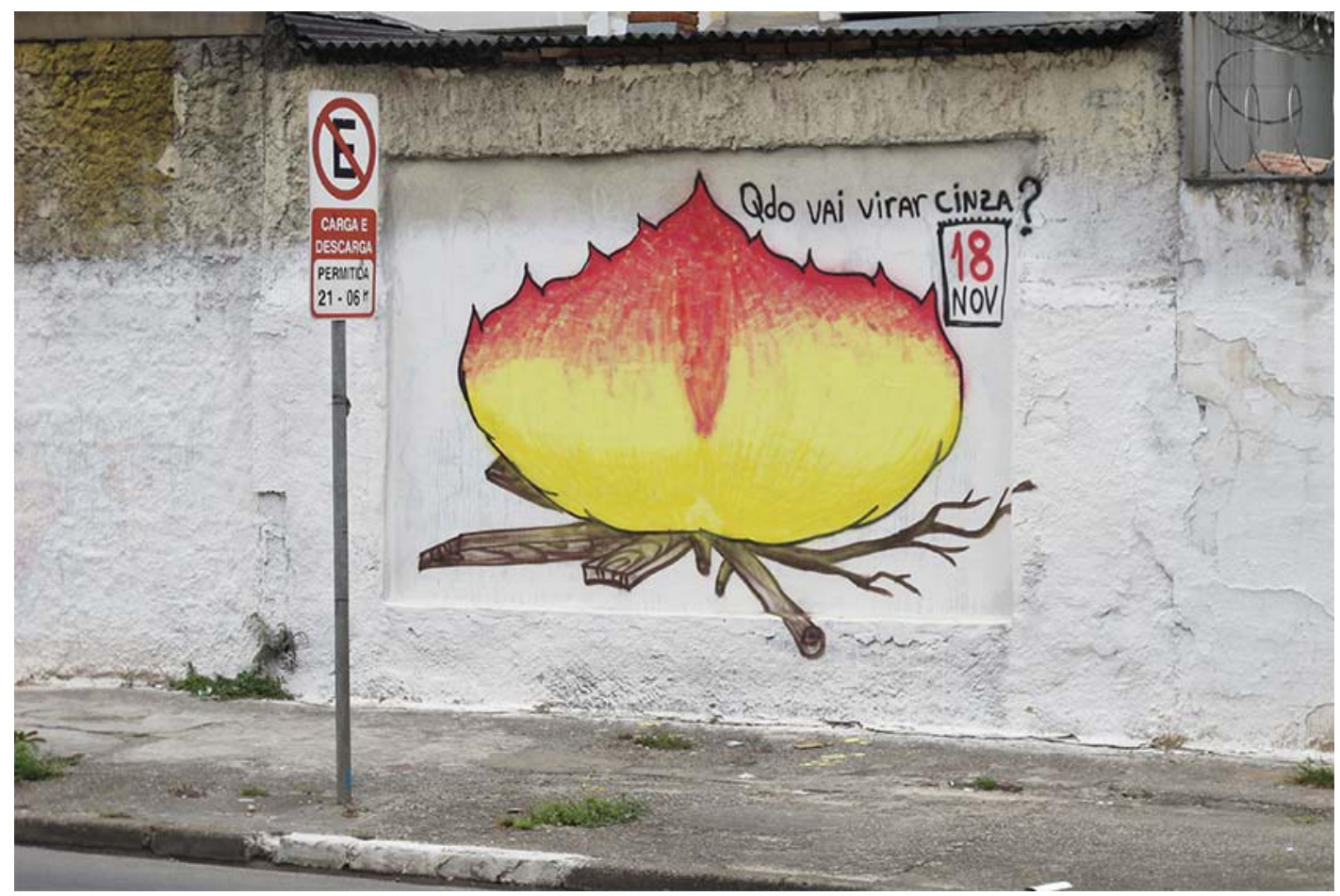

Grafite ironizando a ação da prefeitura de apagar com tinta cinza as intervenções visuais da cidade, 2011.

\section{ReCONHECIMENTO E MEMÓRIA}

Entre os pixadores, é muito comum ouvir ou vê-los fazendo homenagens a colegas que já morreram. Os relatos das mortes e as homenagens aos falecidos são constantes em suas narrativas e nas marcas que deixam nos muros. Não é difícil observar, ao lado de alguns pixos, as frases: "In memoriam" ou "Esteja em paz". Um dos nomes de destaque, por isso constantemente lembrado e reverenciado, é o de \#DI\#, citado no início desse artigo. Após sua morte, seus amigos mais próximos fizeram uma pequena escultura no formato do seu pixo e o citavam em diferentes momentos como forma de homenageá-lo. Falava-se sobre o \#DI\# em conversas nos points ${ }^{4}$, postagens em fóruns e comunidades virtuais e em produções audiovisuais ou reportagens sobre pixação. Ele é sempre muito lembrado pela maioria dos colegas.

Esses relatos de morte de colegas destacam a importância da memória e ressaltam a necessidade de se lembrar dos companheiros já falecidos. $\mathrm{O}$ respeito à memória dos mortos é evidenciado também no modo como a maioria aborda uma prática considerada execrável, a de "atropelar" a inscrição do outro. Atropelar é a forma como denominam o ato de passar por cima da intervenção visual alheia, ou, em outras palavras, de pixar sobre o pixo do outro. Não há ofensa maior do que se ter a marca sobreposta por outra. Presenciei muitas discussões e brigas por causa disso. Aquele que atropela as marcas alheias não é bem visto. Por outro lado, quem tem sua inscrição atropelada, caso encontre o atropelador, exigirá satisfações. Além da ofensa

4 Pontos de encontro que os pixadores estabelecem na cidade, para onde convergem jovens de diferentes localidades que combinam de sair para pixar juntos. 
pessoal, os pixadores também destacam a questão do desrespeito à memória dos mais velhos - "os mais antigos" na atividade -, dos mortos e da própria pixação como justificativa para a desqualificação do atropelo. As ações mais rechaçadas envolvem o desrespeito ao pixo de alguém mais velho, que muitas vezes já até havia abandonado o ofício, ou de alguém que já houvesse morrido. Particularmente nesse último caso, o argumento é de que o falecido não poderia voltar para refazer sua marca e, portanto, essa seria uma grande afronta à memória do mesmo e da pixação. Joel Candau (2011: 143) ao discutir a relação entre memória e identidade, afirma o quanto a memória dos mortos é importante para a afirmação de identidades coletivas: "todo indivíduo morto pode converter-se num objeto de memória e de identidade, tanto mais quando estiver distante no tempo". Sendo assim, ao falar de seus colegas mortos, estão ao mesmo tempo anunciando as condições em que vivem, os riscos a que são submetidos e aos quais se submetem e, também, construindo, por meio da prática da pixação, um mecanismo social de memória e de reconhecimento.

Em suas dinâmicas relacionais, os pixadores engendram um importante dispositivo de interação, circulação e memória. Eles estabelecem diversos pontos de encontro em espaços públicos da cidade, como praças, calçadões, parques etc. Destes, o mais importante, no período em que fiz a pesquisa, era o ponto de encontro, denominado por eles como point, que ocorreu entre os anos 2000 e 2005 nas proximidades do Centro Cultural São Paulo, na Rua Vergueiro ${ }^{5}$. Nesse, conhecido como Point da Vergueiro, pixadores de toda a Região Metropolitana de São Paulo encontravam-se às terças-feiras à noite para, entre outras atividades, conversar e contar histórias sobre lugares pixados, "perreios" passados com a polícia, festas de pixadores etc. Contudo, uma das principais ações no point era a combinação de novos rolês ${ }^{7}$. Dessa maneira, a partir de um local específico de encontro semanal, indivíduos e grupos de diferentes regiões, ainda que não se conheçam pessoalmente, trocam informações e combinam de pixar juntos. Quase sempre, esses acordos implicam em um conduzir o outro para deixar suas marcas nos bairros onde moram ou em sair para pixar pelo centro da cidade. Conseguem, assim, ao mesmo tempo, alcançar diferentes objetivos perseguidos por quem pertence a esse circuito ${ }^{8}$ específico da pixação paulistana: deixar sua marca no maior número possível de lugares e o mais distante possível de seu local original de moradia, estabelecer alianças com outros pixadores e, consequentemente, conseguir grande visibilidade entre os colegas, ou, conforme expressão dos próprios: "aumentar o ibope" . Configura-se, assim, uma rede social que permite a jovens, majoritariamente oriundos de bairros pobres da periferia de São Paulo, transitar por diferentes regiões da cidade, centrais ou periféricas, estabelecendo laços de amizade ou, em alguns momentos, de inimizade. Nesse último caso, principalmente quando ocorrem os atropelos.

Essa rede estabelecida pelos pixadores em São Paulo desenvolve-se por meio de dinâmicas muito particulares de interação. Uma destas, que em grande medida dispara todas as outras relações, ocorre por meio do contato inicial que eles estabelecem entre si para assinar as suas

5 Em 2005, o point central dos pixadores muda-se para outro local do centro da cidade, devido à repressão policial na Rua Vergueiro.

6 Perreio é o termo utilizado para relatar situações que envolviam dificuldades, embaraços ou mesmo perigo. $\mathrm{O}$ mesmo que apuro.

7 Modo como designam as saídas para pixar. Para uma descrição mais detalhada dos rolês e dos points dos pixadores, ver Pereira (2007).

8 A categoria circuito é desenvolvida por Magnani (2002) e refere-se ao exercício de uma determinada prática ou estabelecimento de certos serviços em espaços não contíguos na paisagem urbana, mas reconhecidos em seu conjunto por quem os frequenta.

9 Referência ao instituto de opinião pública que afere a audiência de emissoras de rádio e televisão. 
folhinhas. Observei no point, muitas vezes, pessoas que não se conheciam abordando-se para perguntar o que o outro pixava e de qual quebrada ${ }^{10}$ vinha. Após essa primeira apresentação, quase sempre um pede ao outro para que assine o seu pixo numa folha de papel. Num mesmo papel, geralmente, assinam vários indivíduos. Algumas vezes são utilizados também cadernos e/ou agendas como suporte para as assinaturas. As folhinhas são guardadas em pastas. Muitos constituem grandes acervos delas. $\mathrm{O}$ tamanho do acervo de folhinhas - além do maior número de lugares pixados, preferencialmente em lugares de visibilidade e risco - confere prestígio, ou ibope, diante dos pares. As folhinhas dos mais velhos e/ou há mais tempo em atividade ou dos que já haviam morrido possuem maior valor. Alguns chegam a vender estas mais valiosas. As folhinhas são, portanto, o principal registro escolhido para conservar uma memória de sua prática. Em outras palavras, ainda que a questão da memória seja acionada o tempo todo, a principal política de patrimônio desenvolvida por eles é a troca e a guarda das folhinhas. Além disso, no acervo constituído por alguns há também fotografias, recortes de matérias jornalísticas sobre a pixação e convites para festas ${ }^{11}$.

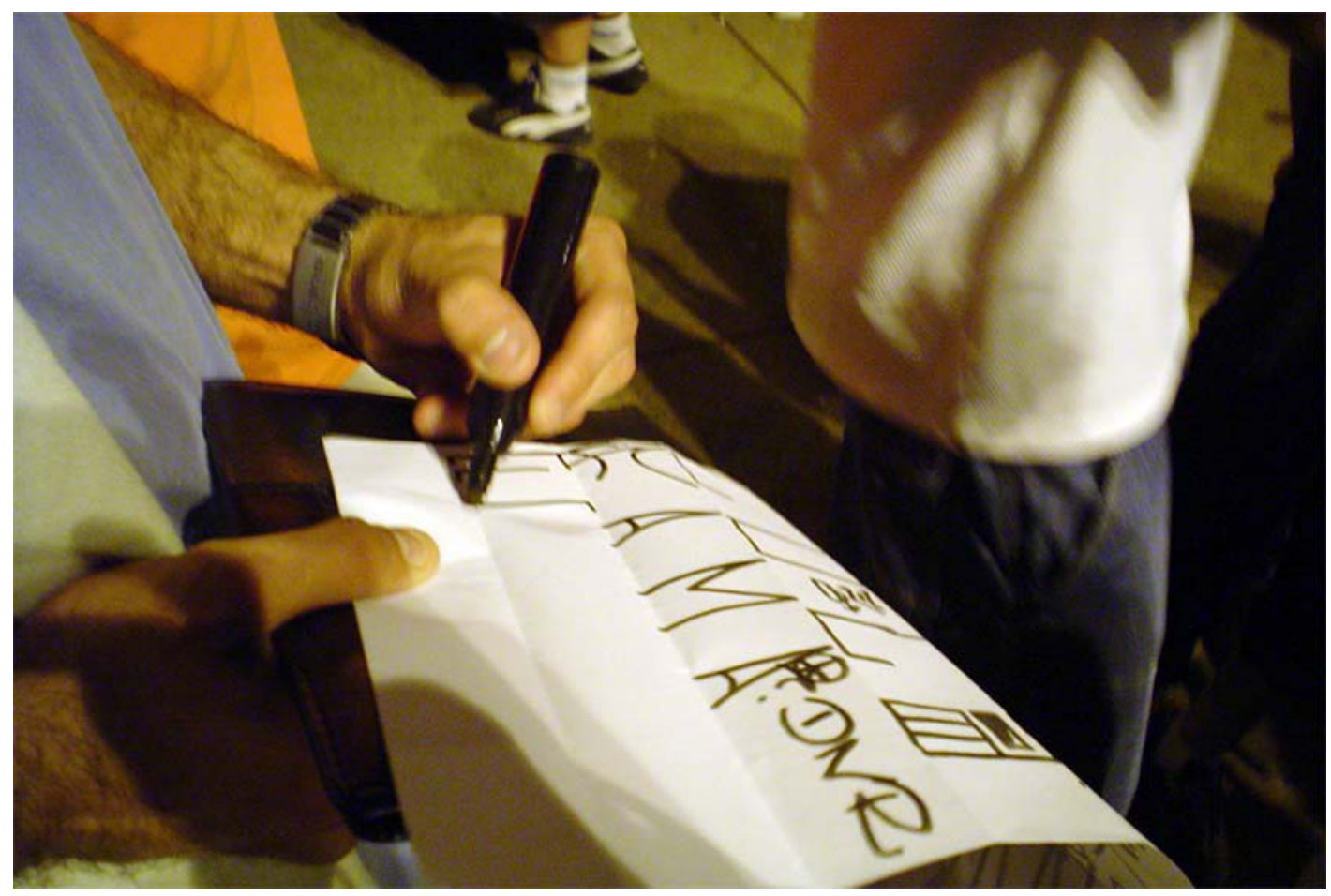

Assinando folhinhas no antigo "Point da Vergueiro", em frente ao Centro Cultural São Paulo, em 2003.

O registro, principalmente em vídeo, do ato da escrita da pixação é outra prática recorrente. O que implica tanto em registrar os próprios atos e os dos amigos, como em deixar-se ser filmado

10 Quebrada é um termo muito usado por diferentes coletivos juvenis para designar bairros de periferia que seriam marcados por pobreza e violência, mas também por certos laços sociais considerados como mais próximos e/ou solidários. Tem-se, portanto, nessa ideia de quebrada, certa ambiguidade, pois a mesma pode ser vista tanto sob a ótica das carências, como de afirmações positivas de laços de sociabilidade e/ou de força moral.

11 Festas de pixação na verdade, cujos convites tem uma apresentação estética muito parecida com as das folhinhas, pois neles assinam os pixadores que apoiam a realização da festa. Além das assinaturas, há a descrição do motivo da festa, muitas vezes a comemoração do aniversário de surgimento do pixo, e um mapa de com as indicações de como chegar ao local servindo-se do transporte coletivo. Os convites são, geralmente, distribuídos no point. 
por outras pessoas que não pertencem à pixação, tais como jornalistas, videodocumentaristas e pesquisadores. Os pixadores mostram-se sempre muito solícitos na concessão de entrevistas ou poses para imagens em vídeos ou fotografias, preferencialmente pixando. Alguns desses vídeos tiveram seus lançamentos divulgados no Point da Vergueiro, entre eles, o intitulado "Pixadores em Ação", lançado ainda em VHS, no início dos anos 2000, fez muito sucesso na época em que comecei minha pesquisa de campo. Esses vídeos, em sua maioria, são comercializados no piso subterrâneo, dedicado ao hip hop e congêneres, da galeria da Rua 24 de Maio no centro de São Paulo, também conhecida como Galeria do Rock. Importante frisar que os vídeos produzidos por pessoas ligadas de forma mais direta à pixação têm a característica bastante peculiar de ressaltar seus autores em ação, como aponta o nome de um dos filmes, mas, principalmente, em ações de risco, pixando o topo de prédios ou dependurando-se em janelas.

Além das folhinhas e dos vídeos, é importante refletir sobre o modo como o próprio ato de inscrever nomes e símbolos com traços pontiagudos na paisagem urbana estabelece - sob diferentes perspectivas - dinâmicas ou ações associadas à questão da preservação da memória ou da fixação da história da atividade em São Paulo. Uma das acusações que se faz aos pixadores é a de conspurcar a memória da cidade, pois eles não respeitariam os bens históricos, principalmente os prédios tombados e os monumentos antigos, como os da Ladeira da Memória, no centro de São Paulo. Considerada o monumento mais antigo da cidade, a Ladeira da Memória, próxima à saída da estação Anhangabaú do metrô, foi, ironicamente, um dos primeiros locais de encontro de pixadores no centro de São Paulo. Todo marcado pelas inscrições dos jovens, o point da Ladeira da Memória antecedeu o Point da Vergueiro. A mudança de um local para o outro aconteceu devido a pressões de determinados segmentos sociais pela recuperação do monumento.

No final dos anos 1990 e início dos 2000, a administração municipal da época iniciou um plano de recuperação do monumento da Ladeira da Memória e impediu, com a presença constante de agentes da guarda civil metropolitana, a concentração de pixadores no local. Tentou-se preservar, assim, uma parte da história da cidade. Porém, há que se indagar, qual e de quem? Porque, talvez para espanto dos defensores do patrimônio e dos bens históricos urbanos, principalmente daqueles de "pedra e cal"12, os jovens pixadores também se mostram preocupados com a história e com a memória. E é justamente essa preocupação com a memória e a história da pixação que faz com que muitos deles deixem suas marcas em prédios históricos, bens tombados e monumentos importantes da cidade. Primeiro, porque neles haveria maior repercussão entre os colegas, que veriam a marca e comentariam a ousadia no point, saudando o autor quando o encontrasse, e também entre certos segmentos da imprensa que possivelmente realizariam alguma matéria sobre o ato de vandalismo contra um bem considerado importante. No caso das reportagens, haveria fotos da pixação, o que contribuiria para divulgar ainda mais a ação. As matérias jornalísticas, aliás, são guardadas como recordação no acervo de folhinhas. Além disso, e esse é o segundo motivo, as estruturas dos edifícios e bens históricos quase sempre são de pedra ou de materiais antigos que não podem ser pintados e que, por isso, proporcionam uma maior perenidade à pixação. Nesses materiais, seria mais difícil a remoção da marca. Desse modo, a própria proposta de preservação dos bens arquitetônicos, levantada principalmente pelos defensores dos patrimônios de pedra e cal, tem contribuído para a dinâmica da pixação em sua busca por visibilidade e memória.

12 A noção refere-se à escolha de bens arquitetônicos como principal objeto das políticas públicas de patrimônio cultural no Brasil. Nos últimos tempos, entretanto, tem ganhado força propostas alternativas que enfocam a ideia de patrimônio imaterial. Para uma discussão mais aprofundada sobre a noção de patrimônio de pedra e cal, ver Gonçalves (2009) e Fonseca (2009). 
“Quem não é visto, não é lembrado”, é uma expressão dita várias vezes pelos pixadores. Ela remete, em grande medida, à lógica seguida pela maioria deles. Nessa busca por ser visto e lembrado - principalmente pelos outros colegas pixadores, é importante ressaltar - estabelecese uma disputa com a dinâmica da cidade e com a tão comum aversão à pixação. Em outras palavras, se eles querem a conservação de suas marcas o maior tempo possível na paisagem urbana, grande parte dos outros citadinos quer extirpá-la. Uma pixação já pode, para desespero dos seus autores, ser apagada na manhã seguinte de sua realização, por isso a busca por lugares de grande visibilidade e por superfícies que conferissem maior permanência. Abaixo, um jovem do município de Diadema, na Grande São Paulo, falou-me um pouco dessa constante preocupação pela conservação de suas marcas.

O que é muita treta também é você ver um pixo do começo, tem muito tempo que você lançou e quando você chega para ver, apagaram. Outra treta é a gente pegar e fazer o nosso barato, e pintarem logo atrás. Por exemplo, eu fiz um rolê na zona leste com o GDC, na hora que a gente desceu do busão,já pegou e fez o pixo, plena tarde, aí a gente saiu fora, e na volta do show, o maluco já tava pintando. Isso deixa a gente injuriado. Isso desanima mesmo, é sem chance (Sombras 2003).

Engendra-se, dessa forma, uma grande disputa entre a efemeridade da atividade e de seu suporte, a paisagem urbana, e a busca pela perenidade, por ser lembrado e por entrar para a história, não a oficial, dos monumentos e dos personagens consagrados, mas a história da pixação, uma história de jovens marginalizados e de suas relações de sociabilidade no contexto metropolitano. Por isso, numa análise mais detida, pode-se depreender que o próprio ato de pixar, de grafar uma inscrição num muro ou no alto de um edifício, mobiliza essa dimensão da memória que quero aqui enfatizar. $\mathrm{Na}$ verdade, o elemento principal que se fixa ao gravar um nome na paisagem é a aventura de alcançar um determinado ponto, seja ele um muro mais baixo num bairro do outro lado da cidade ou o alto da fachada de um prédio na região central. A designação do ato de sair para pixar como rolê evidencia, portanto, a importância dessa circulação pela cidade e também o quanto essa escrita da pixação registra esses percursos pelo espaço urbano. A expressão "sair para dar um rolê" é muito comum em outros contextos majoritariamente juvenis e refere-se, nesses outros usos, a saídas para dar uma volta ou para se divertir. No caso específico da pixação, rolê diz respeito também e, principalmente, ao ato de sair para pixar a cidade. Eles se referem aos que têm muitas marcas pela paisagem urbana como indivíduos que "têm muito rolê".

De certa forma, na pixação ocorre uma recriação do espaço urbano, com a construção de novas referências, convertendo-o em espaço de memória para os que participam dessa atividade. Ao organizar o espaço materialmente ou ao transformá-lo à sua imagem, é a transmissão de certa memória coletiva o que se tentava garantir. Ao seguir a perspectiva levantada por Maurice Halbwachs (1990), de que o espaço é um importante suporte para a memória, pode-se apreender a pixação como um modo de representar o espaço urbano e, portanto, de construir uma memória coletiva sobre o mesmo ou de articular na paisagem urbana referências de memória. Percorrer a cidade sob a perspectiva da pixação é estar atento à paisagem, observar muros, edifícios, monumentos, para tentar identificar marcas recentes, descobrir novos espaços para se pixar e relembrar histórias de pixações já gravadas há algum tempo. Nesse último caso, conta-se quem era o autor ou particularidades de como tal marca teria sido ali deixada. Certa vez, ao visitar um point no bairro da Lapa, acompanhado por um pixador, este me disse que sabia que estávamos chegando ao local de encontro por causa das pixações nos prédios. Contou-me que muitas vezes utilizava-se desse recurso para se orientar na cidade, sabia que já passara por algum lugar antes por recordar das inscrições observadas anteriormente. 


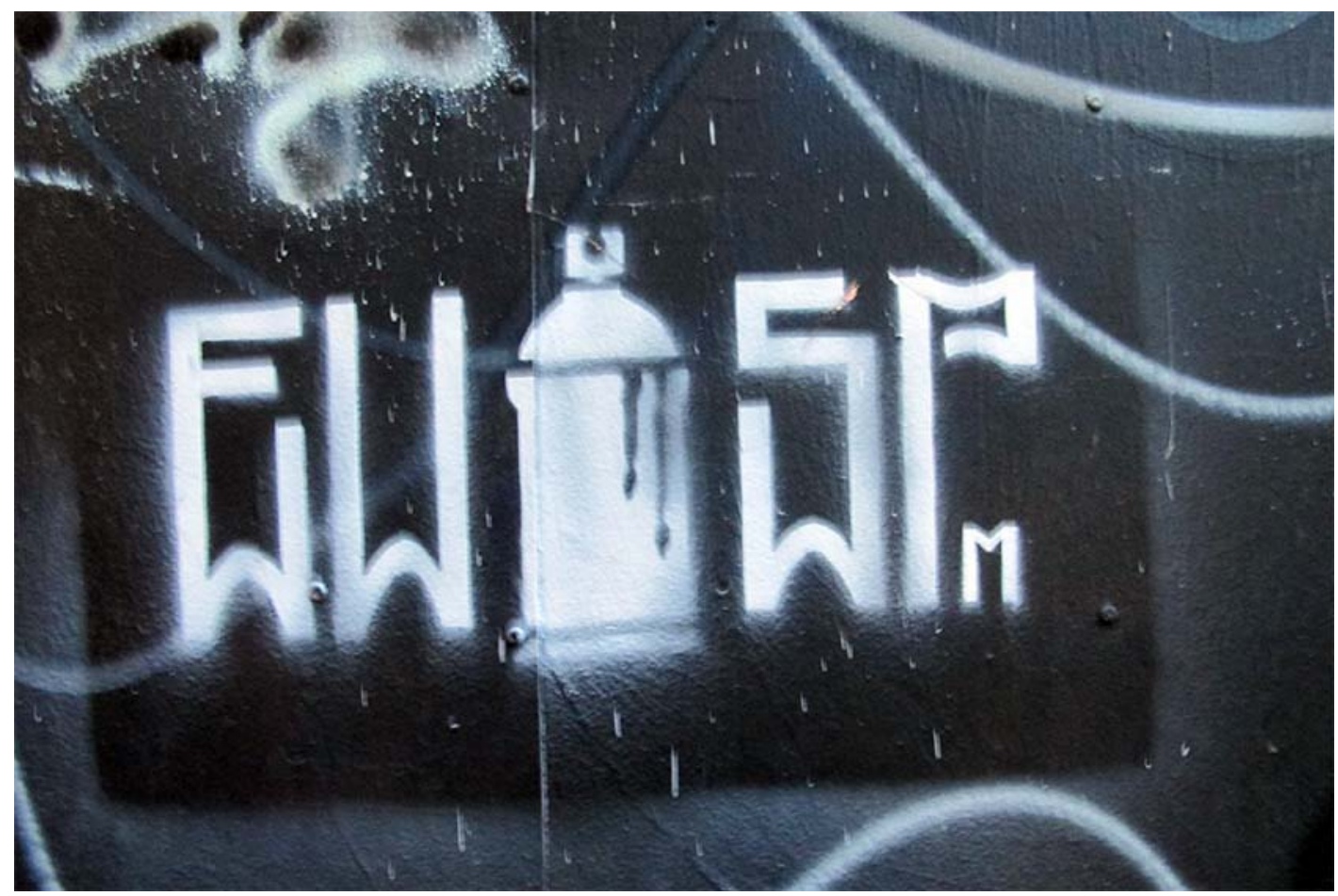

Grafite e pixação usam o mesmo instrumento, a tinta "spray”, e o mesmo suporte, a paisagem urbana, 2012.

A escala metropolitana de São Paulo permite, portanto, a criação das dinâmicas específicas da pixação paulistana, mas, ao mesmo tempo, por meio destas, os pixadores recriam a metrópole ao seu modo, registrando nela suas marcas de referência e inventando uma nova cidade. Michel Agier (2011:55) discute o processo pelo qual os sujeitos às margens inventam por si a sua própria existência por meio da noção de "fazer a cidade": "são as pessoas que fazem a cidade, os grupos sociais que fazem a cidade, e não a cidade que faz a sociedade". Nessa criação de um espaço próprio, de uma cidade da pixação, há um uso tático, no sentido exposto por Michel de Certeau $(1994)^{13}$, das estruturas físicas e sociais da cidade em que - ao contrário do flâneur parisiense descrito por Walter Benjamin (2007), cujo trajeto conduz a um tempo que desapareceu - o registro do trajeto no presente está em busca de um passado porvir. Recuperando a dimensão social ou coletiva da memória, afirmada por Halbwachs, Joel Candau (2011) discute a relação entre a dimensão da memória e os processos de afirmação identitária. Esse autor afirma que o homem utilizar-se-ia de elementos exteriores para ampliar sua memória. Essa exteriorização permitiria a transmissão memorial. Ela traduziria a vontade de produzir traços a fim de compartilhar sinais transmitidos e, assim, fazer memória.

Heródoto escrevia "para impedir que não desapareça o que fazem os homens", nem para que se torne anônimo, sem identidade, com o projeto de fazer entrar nas memórias não apenas o tempo longínquo das origens, mas aquele dos acontecimentos próximos (Candau,2011: 107).

Esse autor apresenta a relação entre a nomeação, a memória e a identidade. Segundo ele, toda nominação de um indivíduo ou de um conjunto de indivíduos tende a afirmar a identidade e a memória de um grupo ou sujeito, seria o nome o local da inscrição do social sobre uma pessoa. Nesse sentido, não se lembrar do nome de uma pessoa pode soar ofensivo para esta. Quando

13 A noção de tática, segundo Michel de Certeau, refere-se a procedimentos criativos do cotidiano que se contrapõem ou produzem alternativas às grandes estratégias de controle e/ou de exercício de poder, configurando uma rede de antidisciplina. 
se trata de alguém ligado à pixação, é bastante comum a manifestação de descontentamento quando alguém afirma não conhecer o seu pixo. Ou seja, não dizer que já viu o nome que se marca na paisagem urbana significa dizer que o interlocutor não tem grande visibilidade na cidade, não tem ibope e, portanto, não faz muitos rolês, não circula pela cidade.

Os nomes que adotam e grafam nos muros da cidade remetem a muitas memórias: a da aventura do momento em que tal inscrição foi grafada, a da formação do grupo ou do início na pixação, a das relações de sociabilidade que a dinâmica contém e mesmo de orientação sobre lugares pelos quais já se circulou. $\mathrm{O}$ pixador possui um olhar atento para a paisagem urbana, buscando, ao mesmo tempo, ver quem está em destaque, quais são as novas pixações e quais são os espaços vazios para inserir sua marca, registrando a memória do seu rolê. Dessa forma, a pixação paulistana apresenta-se como um complexo dispositivo juvenil de, em meio ao anonimato que uma metrópole como São Paulo propicia, afirmar um nome e tornar-se assim conhecido, configurando, ao mesmo tempo um processo de identificação - entendido aqui, conforme afirma Michel Agier (2011), num sentido situacional e não substancial - e uma memória - como apontado por Halbwachs e Candau.

\section{A ESCRITA dA PIXAÇÃo}

A pixação, escrita assim mesmo com “ $x$ ”, conforme o uso feito pelos próprios pixadores, poderia sinalizar apenas uma suposta ignorância das regras gramaticais, visto que a grafia correta da palavra seria pichação com "ch", mas é colocado por eles como uma maneira de diferenciar a sua prática da definição comum de pichação. $O$ que fazem não seria simplesmente pichar um nome, uma palavra ou uma frase qualquer numa parede, mas sim pixar a sua marca feita, ou melhor, desenhada com letras estilizadas, contorcidas e com um formato anguloso. Não se pixa de qualquer modo, com qualquer letra, mas com um formato previamente elaborado, com tipos de letras criadas pelos próprios, demonstrando um padrão estético peculiar. Além disso, há um diálogo com o espaço urbano, com o local onde esta marca será "lançada", é preciso que ela esteja em local de grande destaque na cidade. Obter grande visibilidade é outro fator que torna uma pixação ainda mais atraente.

Embora não problematizem muito o significado dos nomes que adotam como seus pixos, dando muitas vezes mais importância à forma do que ao conteúdo do que é pixado, os nomes com os quais os pixadores marcam a cidade são bem peculiares e têm diversos motivos como inspiração. Porém, há algumas recorrências de temas como sujeira, criminalidade, marginalidade, violência, morte, transgressão, drogas e loucura.

O nome de um pixo é único, por isso não pode haver outra turma com a mesma denominação na cidade. Quando se descobre que há outro grupo homônimo, logo se tirará satisfações com este. Nestes casos, o critério mais comumente adotado, segundo eles, para definir qual deles deve manter a denominação utilizada é o tempo. O pixo mais antigo tem mais legitimidade, por isso os seus proprietários têm o direito de continuar utilizando a alcunha. Assim, aqueles que utilizam o nome há menos tempo reconhecem a legitimidade daqueles há mais tempo em atividade e simplesmente trocam o nome de seu pixo. Há ainda casos em que os dois grupos acabam se unindo e passam a pixar juntos. Quando isto acontece, a única exigência posta é que o grupo mais novo adote o mesmo desenho, a mesma forma, das letras utilizadas por aqueles 
que já pixavam a marca anteriormente. Isto demonstra que o formato dado às letras prepondera sobre o significado da palavra. Dessa maneira, tanto o nome utilizado para se pixar, quanto a forma conferida a este pela estilização das letras é e deve ser única, sendo exclusiva do grupo ou do indivíduo que a criou.

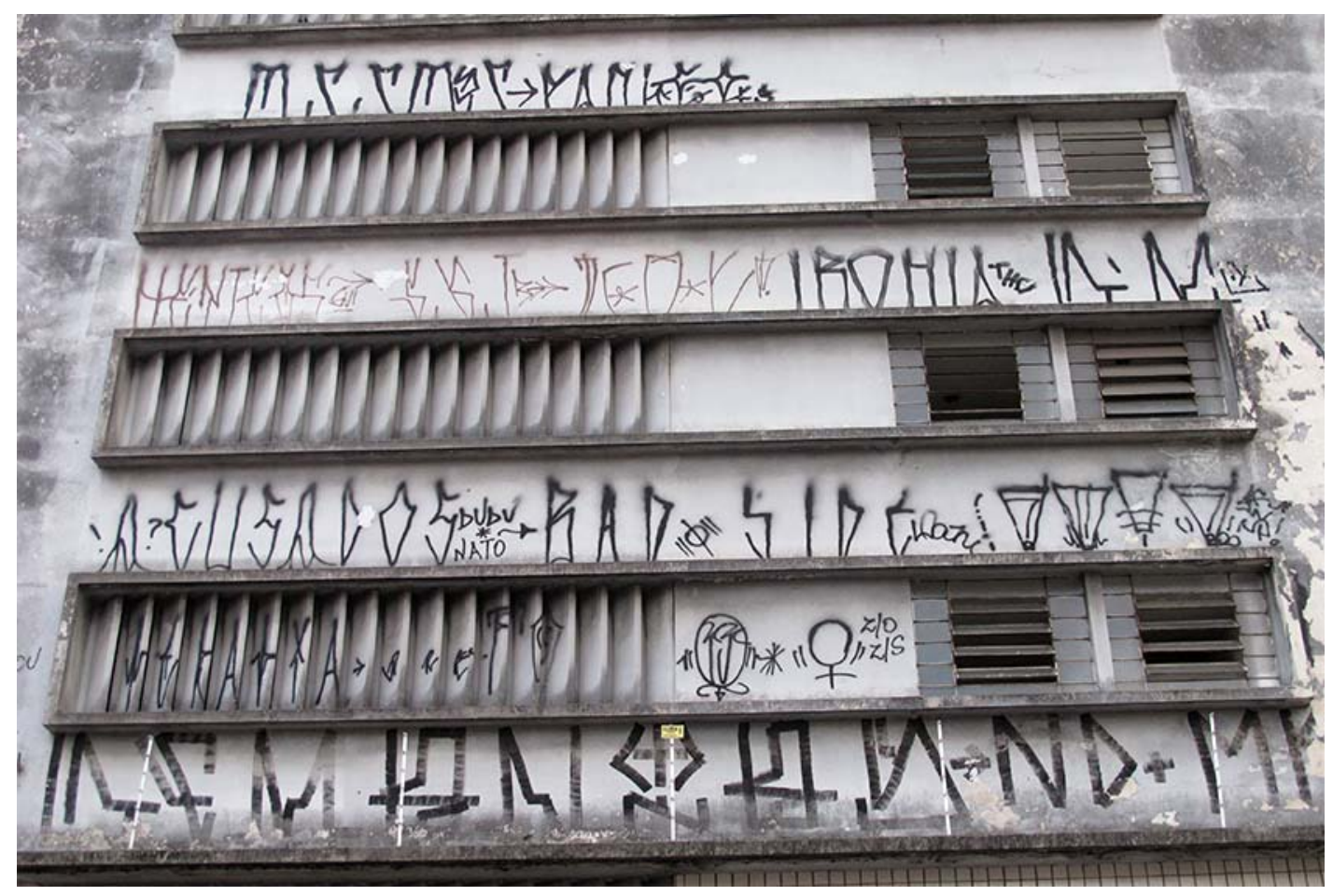

A escrita da pixação paulistana, 2012.

A escrita, conforme Angela Kleiman (1995), seria uma "tecnologia" de comunicação que sustentaria o poder. Lévi-Strauss (1996) também afirma a dimensão política da escrita. Em Tristes Trópicos, ele descreve um episódio no qual, em incursão pelos sertões brasileiros, encontra uma liderança Nambiquara que simulou desvendar a escrita dos brancos e traçou algumas linhas num papel para comunicar-se com eles, de modo a mostrar aos seus companheiros que conseguira comunicar-se com os brancos. A partir desse fato, Lévi-Strauss reflete sobre essa "coisa estranha" que é a escrita. $\mathrm{O}$ autor discute quais seriam os fatores que diferenciavam os povos com e sem escrita. Segundo ele, os povos com escrita desenvolveriam uma grande capacidade de preservar os conhecimentos e deteriam uma maior consciência do passado que levaria a uma maior habilidade em organizar o presente e o futuro, pois a escrita tornar-se-ia uma memória artificial. Ele (1996: 283) afirma ainda que a escrita relacionar-se-ia intrinsecamente com a formação das cidades e dos impérios. Ou seja, a escrita levaria a uma "integração em um sistema político de um número considerável de indivíduos e sua hierarquização em castas e em classes". A função mais elementar da escrita seria, conforme essa perspectiva, garantir a submissão e/ou servidão de outros. A escrita teria sido essencial para fortalecer as dominações: "A luta contra o analfabetismo confunde- se, assim, com o fortalecimento do controle dos cidadãos pelo Poder. Pois é preciso que todos saibam ler para que esse possa afirmar: ninguém deve alegar que desconhece a lei”(Lévi-Strauss 1996: 283).

Em suas reflexões sobre a distinção entre escrita e oralidade e sua suposta relação com as ideias de pensamento concreto e abstrato, Jack Goody (1988) não apenas retoma a discussão de 
Lévi-Strauss em o Pensamento selvagem, como também dialoga com a concepção da escrita, presente em Tristes Trópicos, como instrumento de poder e dominação. Apesar de partir da dicotomia entre a oralidade e a escrita, Goody crítica essa apreensão dual que atribui modos diferentes de pensar entre sociedades primitivas e avançadas e que estabeleceria a grande dicotomia entre "nós e eles". Menos do que se ater às diferenças incutidas nos modos de pensar, Goody (1988: 168) propõe-se a entender a passagem da ciência do concreto à ciência do abstrato, ou o desenvolvimento de conceitos e formulações cada vez mais abstratos, a partir da análise "das transformações fundamentais produzidas na natureza da comunicação humana". Defende Goody que mesmo em sociedades com escrita, principalmente naquelas em que há um domínio da escrita por um grupo específico, as relações entre esta e a oralidade seriam bastante imbricadas. Não existiria, portanto, um movimento único no modo como a oralidade nas sociedades com escrita seria influenciada pelos meios escritos de comunicação. Haveria, assim, diversas formas de interação entre oralidade e escrita, inclusive a influência da primeira sobre a segunda.

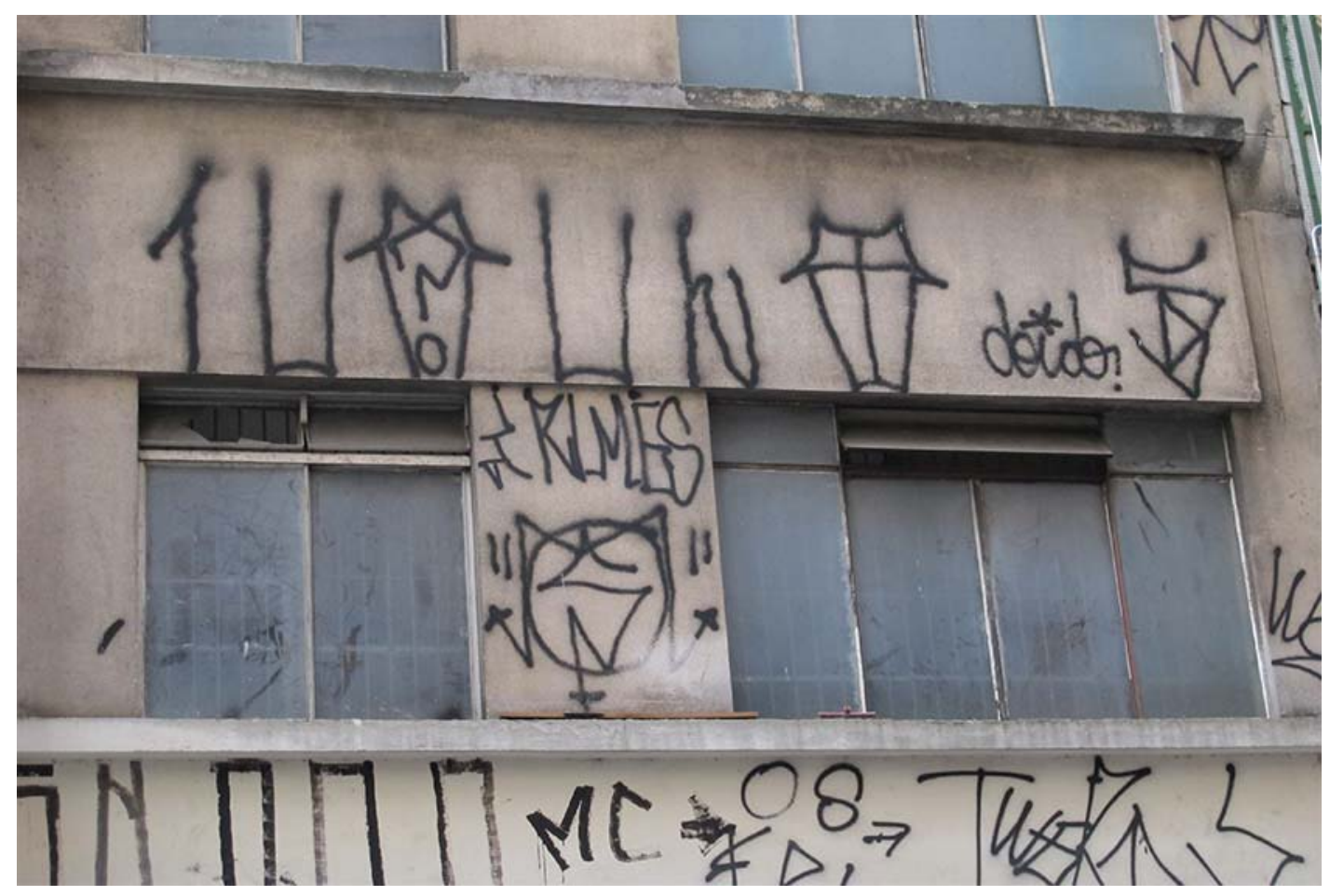

A escrita da pixação paulistana, 2012.

Se a escrita permite uma ampliação da consciência da história, também entre os pixadores ela desenvolvia um papel importante para o registro de sua história, ainda que estas sejam escritas e histórias um tanto quanto particulares. Trata-se, por um lado de escritas de contraposição à organização espacial da cidade por meio de grafias ininteligíveis para grande parte do restante da população, vista como sujeira, agressão e vandalismo. E, por outro lado, como já exposto, de uma apropriação lúdica da escrita que não se importa tanto com o que se escreve, mas sim com o modo como se escreve, pois a estilização conferida às letras dos nomes grafados nos muros adquire maior importância do que o próprio significado dos termos. Assim, na escrita dos muros, o significado subordina-se à forma das letras. Essa particularidade ocasiona na dificuldade de entendimento daqueles que não pertencem ao circuito da pixação. Isto acontece não porque 
utilizam um código apenas compreendido por eles, mas porque a estilização conferida às letras é um elemento que apenas faz sentido para quem é adepto dessa prática.

Jovens de diferentes regiões da cidade estabelecem contatos entre si e sabem quem que, na paisagem urbana, escreve aquela marca, com aquele formato específico. Por isso, a prática de "lançar" palavras estilizadas nos muros é mais voltada para eles mesmos, ou, como me disse, certa vez, um famoso e veterano pixador: para quem sabe "ler o muro". Ele me contou que há outras pessoas que não pixam, mas que também sabem ler o muro como eles e que, por isso, admiramna. Esta, então, fica como uma definição interessante para a capacidade de compreender essas marcas paulistanas: "saber ler o muro". O que não significa, entretanto, entender completamente o que querem dizer aquelas inscrições nos muros, compreender qual é o nome ali escrito, mas conseguir lê-las na lógica dos pixadores e de suas relações entre si e com a cidade. Entender que aquele pixo no centro de São Paulo é de um grupo de jovens de um bairro da zona leste, que se conheceu no point dos pixadores. Ou seja, somente quando se observa estas inscrições na paisagem urbana e se é capaz de remeter seus significados ao contexto das relações sociais de onde elas vêm é que se torna possível entender, ou ler, esta tão diferente e, para muitos, também perturbadora manifestação destes jovens arteiros numa metrópole como São Paulo.

\section{REFERÊNCIAS BIBLIOGRÁFICAS}

Agier, Michel. 2011. Antropologia da cidade: lugares, situações, movimentos. São Paulo: Editora Terceiro Nome.

Benjamin, Walter. 2007. Passagens. Belo Horizonte/São Paulo: Editora da UFMG/Imprensa Oficial do Estado de São Paulo.

Candau, Joel. 2011. Memória e identidade. São Paulo: Contexto.

Certeau, Michel de. 2009. A invenção do cotidiano: artes do fazer. Petrópolis, RJ: Vozes.

Fonseca, Maria Cecília Londres. 2009. "Para além da pedra e cal: por uma concepção ampla de patrimônio cultural."Pp.59-70 in Memória e patrimônio: ensaios contemporâneos, organizado por abreu, R. e chagas, M. Rio de Janeiro: Lamparina.

Franco, Sérgio. 2010. "Pixação e as aves de rapina.” in Le Monde Diplomatique Brasil.

Gonçalves, José Reginaldo. 2009. “O patrimônio como categoria de pensamento.” Pp. 25-33 in Memória e patrimônio: ensaios contemporâneos, organizado por Abreu, R. e chagas, M.. Rio de Janeiro: Lamparina.

Halbwachs, Maurice. 1990. A memória coletiva. São Paulo: Edições Vértice/Editora Revista dos Tribunais.

Goody, Jack. 1988. Domesticação do pensamento selvagem. Lisboa: Editorial Presença.

Kleiman, Angela. 1995. "Modelos de letramento e as práticas de alfabetização na escola." Pp.

15-61 in Os significados do letramento: uma nova perspectiva sobre a prática social da escrita.

Campinas, organizado por Kleiman, A. São Paulo: Mercado de Letras.

Lévi-strauss, Claude. 1996. Tristes Trópicos. São Paulo: Companhia das Letras.

Magnani, José Guilherme. 2002. "De perto e de dentro: notas para uma etnografia urbana." Revista Brasileira de Ciências Sociais, 49(17): 11-29.

Medeiros, Daniel - Boleta. 2006. Ttsss... A Grande Arte da Pixação em São Paulo, Brasil. São Paulo: Editora do Bispo.

Pereira, Alexandre Barbosa. 2007. "Pichando a cidade: apropriações "impróprias" do espaço 
urbano.” Pp. 225-246 in Jovens na metrópole: etnografias de circuitos de lazer, encontro e sociabilidade, organizado por Magnani, J. e Mantese, B. São Paulo: Editora Terceiro Nome.

Materiais e periódicos consultados:

Álbum de Cromos SóPixo, s.d.

Folha de S. Paulo, 21/01/2006.

Folha de S. Paulo, 11/12/2008.

(http://www1.folha.uol.com.br/folha/ilustrada/ult90u477915.shtml)

Portal G1, 25/09/2010. (http://g1.globo.com/pop-arte/noticia/2010/09/obra-polemica-comurubus-dentro-da-bienal-e-alvo-de-pichacao.html)

"Pixadores em ação" (audiovisual): (http://www.youtube.com/watch?v=gSpUa2oF4wo)

Revista da Folha, Folha de S. Paulo, 26/03/2006.

WHO IS NOT SEEN, IS NOT REMEMBERED: SOCIABILITY, WRITING, MEMORY AND VISIBILIty in SaO PaUlo of tag grafitti

The article discusses how the tag grafitti in the city São Paulo, carried out by young people from the outskirts of Sao Paulo, configures a device of sociability, recognition and memory. Within this context, the one who manages to spray his name in the biggest number and the most prominent of places achieves the highest eminence. The tag grafitti leaves a peculiar written record of these young people in the urban landscape. It makes sense especially for the taggers, as they know to read the walls. Through their writing, they create proper references in the urban space and recreate the city, even when in opposition to the tastes of the majority of the population who does not look favourably upon their activity.

Key words: grafitti tag, sociability, memory, writing, youth, urban landscape 